\title{
Fitossociologia de trechos da vegetação do Complexo de Campo Maior, Campo Maior, PI, Brasil ${ }^{1}$
}

\author{
Ruth Raquel Soares de Farias ${ }^{2,4}$ e Antonio Alberto Jorge Farias Castro ${ }^{3}$
}

Recebido em 08/06/2003. Aceito em 08/06/2004

\begin{abstract}
RESUMO - (Fitossociologia de trechos da vegetação do Complexo de Campo Maior, Campo Maior, PI, Brasil). Com o objetivo de contribuir para o conhecimento da fitofisionomia de transição de uma área no município de Campo Maior, recoberto pela vegetação denominada Complexo de Campo Maior, utilizou-se o método de quadrantes, considerando todos os indivíduos lenhosos incluídos cipós, com diâmetro do caule ao nível do solo (DNS) $\geq 3 \mathrm{~cm}$. Foram alocados 100 pontos em cada área, Alto do Comandante e Baixão da Cobra, situadas na Fazenda Lourdes. Amostrou-se 46 espécies na primeira área e 44 na segunda, totalizando 68 espécies. Os valores de densidade e de área basal foram 2.730 e 2.799ind ha ${ }^{-1}$ e 38,22 e 38,58 $\mathrm{m}^{2} \mathrm{ha}^{-1}$, respectivamente. As espécies com maior Índice do Valor de Importância (IVI) em Alto do Comandante foram Casearia ulmifolia Vahl ex Vent., Aspidosperma subincanum Mart., Combretum leprosum Mart. e Bauhinia ungulata L. A primeira posição de C. ulmifolia foi em conseqüência dos três parâmetros relativos. Apenas as três espécies de maiores IVI contribuíram com os maiores Índices do Valor de Cobertura (IVC). Em Baixão da Cobra, a espécie de maior IVI foi Aspidosperma subincanum Mart., também em conseqüência dos valores dos três parâmetros relativos. Destacou-se ainda, Combretum mellifluum Eichler, Bauhinia pulchella Benth. e Buchenavia capitata (Vahl.) Mart. As quatro espécies com maiores IVI corresponderam as de maiores IVC. O índice de diversidade de Shannon (H') foi de 3,20 e 3,09nats ind ${ }^{-1}$, para o Alto do Comandante e Baixão da Cobra, estes valores podem ser considerados altos quando comparados aos encontrados em trabalhos desenvolvidos na Caatinga, Carrasco e Cerrado no Nordeste brasileiro.
\end{abstract}

Palavras-chave: fitossociologia, ecótono, Campo Maior, Piauí

\begin{abstract}
Phytosociology in parts of vegetation from Campo Maior Complex in Campo Maior Municipality, Piauí State, Brazil). With the purpose to contribute to the knowledge of the phytophysionomy of transition in a area in Campo Maior province, recover for a vegetation denominated Complex of Campo Maior, utilized the Quadrants Method considering all stem diameter of $\geq 3 \mathrm{~cm}$ at the soil level. They were allocated 100 points in each area, Alto do Comandante and Baixão da Cobra, located in Lourdes’ Farm. Were showed 46 species in Alto do Comandante and 44 in Baixão da Cobra, in a total of 68 species. The density values and of basal area were 2,730 and 2,799ind ha $\mathrm{H}^{-1}$ and 38.22 and $38.58 \mathrm{~m}^{2} \mathrm{ha}^{-1}$, respectively. The species with major rate of importance value (IVI) in Alto do Comandante were Casearia ulmifolia Vahl. ex Vent., Aspidosperma subincanum Mart., Combretum leprosum Mart. and Bauhinia ungulata L. The first position of $C$. ulmifolia was in consequence of three relative parameter. Only three species of major IVIs contributed with the majors rate of covering value (IVC). In Baixão da Cobra, the specie of major IVI was Aspidosperma subincanum Mart, also in consequence of three relative parameters values. Combretum mellifluum Eichler, Bauhinia pulchella Benth. and Buchenavia capitata (Vahl.) Mart. also stood out. The four species with major IVI corresponded with that ones of major IVC. The rates of diversity of Shannon (H') was 3.20 and 3.09nats ind ${ }^{-1}$ to Alto do Comandante and Baixão da Cobra, this values can be considered high when compared with the values found in works developed an Caatinga, Carrasco and Cerrado Brazilian Northeast.
\end{abstract}

Key words: phytosociology, ecotone, Campo Maior, Piaui State, Brazil

\section{Introdução}

O Nordeste brasileiro ocupa área de $1.548 .672 \mathrm{~km}^{2}$ (Pauwels 1985) dos quais $960.461 \mathrm{~km}^{2}$ (62\%) têm sido considerados como semi-árido (Mello Netto et al. 1992). Entretanto, Sousa et al. (1994), com base na isoieta modal de $800 \mathrm{~mm}$ ano $^{-1}$ e em critérios de natureza geo-ambiental, afirmaram que a área do semi- árido é de 788.064km², onde a precipitação média anual varia de 400 a $800 \mathrm{~mm}$ e que, além da vegetação caducifólia espinhosa da caatinga, ocorrem tipos vegetacionais transicionais associados a outras formações de ocorrência natural.

No Estado do Piauí, as formações vegetais sofrem a influência de diferentes domínios, como o Amazônico, o do Planalto Central e o do Nordeste, caracterizando-se

1 Parte da Dissertação de Mestrado do primeiro Autor. Auxílio CAPES

2 Rua Desembargador Manoel Castelo Branco, 1000, CEP 64049-270, Teresina, PI, Brasil

3 Universidade Federal do Piaú́, Núcleo de Referência em Ciências Ambientais do Trópico Ecotonal do Nordeste (TROPEN/UFPI) e Departamento de Biologia, Av. Universitária 1310, Ininga, CEP 64049-550, Teresina, PI, Brasil (aajfcastro@uol.com.br)

4 Autor para correspondência: ruthraquel@ibest.com.br 
por apresentar grande diversidade de ecossistemas, como a floresta latifoliada subcaducifólia, a floresta mista subcaducifolia, a floresta latifoliada caducifólia não espinhosa e as áreas de transição entre mata de babaçu/cerrado, mata seca/cerrado e cerrado/caatinga (CEPRO 1996a).

Nas áreas de transição, que cobrem cerca de 19\% da área total do Estado do Piauí, existe um tipo vegetacional denominado de Complexo de Campo Maior que faz parte das áreas consideradas de tensão ecológica (Rivas 1996), que compõem o maior domínio fitoecológico da bacia hidrográfica do Rio Parnaíba. A maior concentração desta fisionomia vegetal está situada nas unidades geoambientais do Vale do Gurguéia, Tabuleiros do Parnaíba e Baixada de Campo Maior. A Baixada de Campo Maior é ambiente que está sujeito a freqüentes inundações, apresentando caráter de transição tendendo para instável.

Outros biomas destacam-se no Estado, como a Caatinga (37\%), ocorrendo no leste e sudoeste do mesmo, caracterizadas por apresentar porte arbóreo, arbustivo-arbóreo ou arbustivo, com densidades variadas e o Cerrado, com 33\%, colocando o Piauí como o quarto estado brasileiro com maior representatividade por ocupação desta vegetação e o primeiro em relação à região Nordeste (Castro 2000; Castro \& Martins 1999; Castro et al. 1998; Oliveira et al. 1997; CEPRO 1996b).

Devido a escassez de informações em áreas transicionais, o presente trabalho fitossociológico representa a primeira contribuição ao conhecimento da vegetação do município de Campo Maior, PI, pertencente ao Complexo de Campo Maior, portanto objetivou-se caracterizar a composição florística e a estrutura fitossociológica da vegetação.

\section{Material e métodos}

As análises fitossociológicas foram desenvolvidas em duas áreas na Fazenda Lourdes (0451'S e $42^{\circ} 04^{\prime} \mathrm{W}$ ), localizada no município de Campo Maior, pertencente à microrregião de Campo Maior, Piauí (Fig. 1). O tipo vegetacional da região é denominado Complexo de Campo Maior e caracteriza-se por apresentar segundo Köppen, clima tropical subúmido seco ( $\left.\mathrm{C}_{1} \mathrm{WA}_{4}{ }_{4} \mathrm{a}^{\prime}\right)$, com pequena amplitude térmica no verão. A duração do período seco é de seis meses, com temperatura máxima de $35^{\circ} \mathrm{C}$ e mínima de $28^{\circ} \mathrm{C}$. Os solos apresentam horizonte " $\mathrm{B}$ ” latossólico, pouco desenvolvidos, hidromórficos e concrecionários tropicais (CEPRO 1992). O método utilizado na

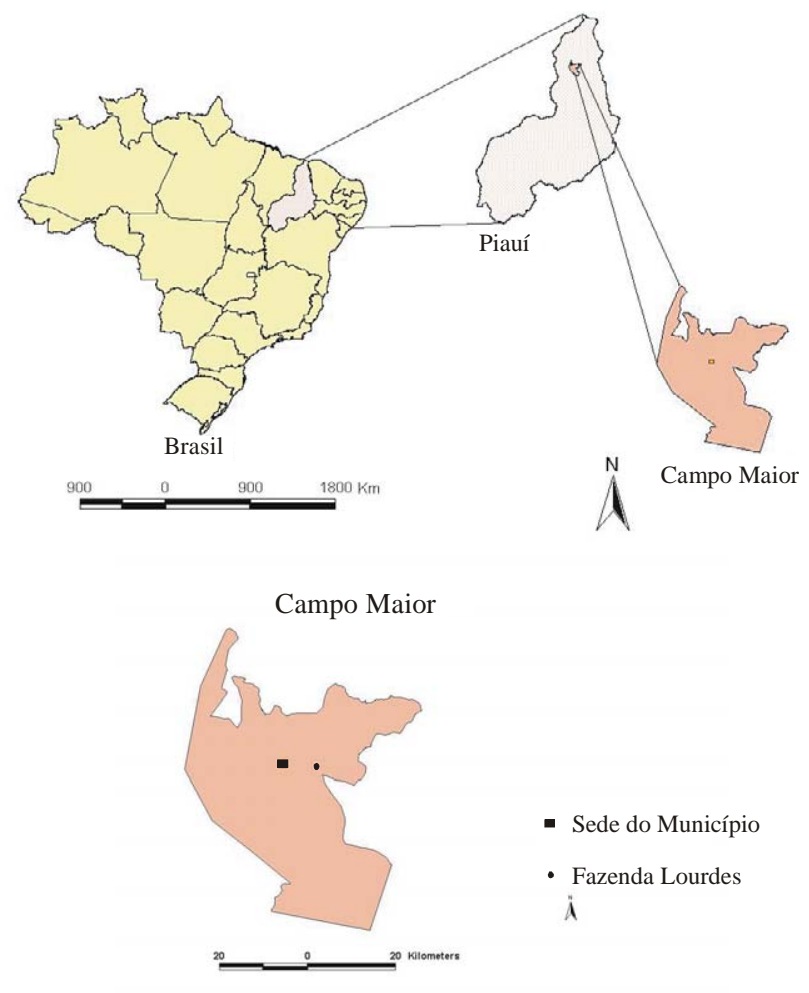

Figura 1. Mapa de localização da área de estudo, Campo Maior, PI, Brasil.

amostragem da vegetação foi o de quadrantes (Curtis \& Macintosh 1950; Martins 1991). A distribuição das unidades amostrais foi efetuada de modo sistemático, com base nos padrões de homogeneidade da vegetação. As duas áreas escolhidas receberam a denominação de “capões” conforme a população local, sendo a primeira denominada Alto do Comandante, com altitude de $120 \mathrm{~m}$ e coordenadas $04^{\circ} 52^{\prime}$ 's e $42^{\circ} 03^{\prime} \mathrm{W}$ e a segunda, Baixão da Cobra, com altitude de $95 \mathrm{~m}$ e $4^{\circ} 52^{\prime}$ 'S e $42^{\circ} 04^{\prime} \mathrm{W}$, as quais são áreas bem preservadas, que melhor caracterizam o mosaico em estudo. O número total de unidades amostrais, 100 pontos em cada área, foi determinado pelo binômio tempo/esforço. A alocação dos pontos amostrais foi feita a cada 10m. Amostrou-se os indivíduos lenhosos, vivos, com diâmetro do caule ao nível do solo (DNS) igual ou superior a $3 \mathrm{~cm}$, exceto as bromeliáceas.

O sistema de classificação adotado foi o de Cronquist (1988) e para abreviatura dos nomes de autores, utilizou-se Brummitt \& Powell (1992).

Os parâmetros fitossociológicos considerados na análise da organização comunitária foram: densidade total, área basal total, freqüência total, altura, diâmetro mínimo, médio e máximo e os parâmetros: densidade, freqüência, dominância, índice do valor de importância 
(IVI) e índice do valor de cobertura (IVC). O índice de diversidade utilizado foi o de Shannon (H'). Nesses cálculos, foi utilizado o programa FITOPAC (Shepherd 1995). O índice de riqueza de espécies aplicado foi o de Whittaker (RE), sendo RE = E/ln (N), onde E é o número de espécies amostradas e $\mathrm{N}$ é o número total de indivíduos amostrados.

Elaborou-se histogramas com os dados de altura a intervalos fixos de um metro, fechado à esquerda e aberto à direita, e os de diâmetro com intervalos de $3 \mathrm{~cm}$, caracterizando-se assim a arquitetura da fitocenose. A definição dos estratos foi realizada segundo Castro (1994).

Em relação às formas de vida, considerou-se nanofanerófitas as espécies cujos indivíduos apresentaram alturas entre 1,0 e 2,0m; microfanerófitas, com alturas de 2,1 a 8,0m; e mesofanerófitas, com alturas acima de 8,1m (Barkman 1978).

Para representação dos perfis fisionômicos da vegetação em estudo, foram sorteados 10 intervalos, cinco em cada capão, de $2 \times 20 \mathrm{~m}$ envolvendo o espaço entre três estacas, representando $20 \%$ da amostra. Todos os indivíduos dentro de cada intervalo foram desenhados esquematicamente.

Para análise entre os dados obtidos e compreensão das relações de similaridade florística, realizou-se a comparação entre os táxons determinados ao nível específico amostrados no Alto do Comandante e Baixão da Cobra, com outros trabalhos quantitativos realizados para vários tipos vegetacionais do Nordeste, tais como M.R. Fonseca (dados não publicados); M.J.N. Rodal (dados não publicados); F.G.Alcoforado Filho (dados não publicados); Araújo et al. (1995); E.M.N. Ferraz (dados não publicados); Figueirêdo et al. (2000) e Lemos \& Rodal (2002) em áreas de vegetação caducifólia espinhosa; Araújo et al. (1998) e Araújo \& Martins (1999), em vegetação caducifólia não espinhosa; Oliveira et al. (1997) e A.P.S. Gomes (dados não publicados), em transição caatingacarrasco; Rodal et al. (1998), em uma vegetação arbustiva perenifólia e Castro (1994) e Conceição (2000), em Cerrado. Através de uma matriz de presença e ausência foram testados os índices de similaridade de Jaccard (IJ) e Sørensen (IS) e elaborados dendogramas por meio do software Krebs for Windows, versão 3.1 (Krebs 1989).

Para identificar os solos presentes nas áreas estudadas foram abertas três trincheiras, uma no Baixão da Cobra e duas no Alto do Comandante por apresentar diferenças estruturais e fisionômicas de solos. Nestas trincheiras, foram identificados os horizontes que compõem o chamado perfil representativo do solo. As amostras coletadas foram enviadas ao Laboratório de Análises de Solo da Universidade Federal do Piauí (LASO), para análises físicas e químicas, seguindo-se a metodologia proposta pela EMBRAPA (1999).

Os dados para obtenção do balanço hídrico, elaborado segundo Thornthwaite \& Mather (1955) foram compilados durante o período de 90 anos (1912a 2001) para o município de Campo Maior, PI, e fornecidos pela Secretaria de Agricultura, Abastecimento e Recursos Hídricos, Departamento de Hidrometeorologia.

\section{Resultados e discussão}

Fitossociologia - Foram determinadas 28 famílias, contendo 54 gêneros e 68 espécies (Tab. 1). Destas, 11 foram consideradas amostráveis, ou seja, atendiam ao critério de inclusão, mas não estavam incluídos nos mesmos (Castro 1994): Caesalpinia ferrea, Cochlospermum vitifolium, Jacaranda brasiliana, Ouratea cearensis, Randia armata, Simarouba versicolor, Tocoyena hispidula e Vitex cymosa no Alto do Comandante e Alibertia edulis, Anacardium occidentale e Copaifera sp. no Baixão da Cobra.

No levantamento fitossociológico, foram amostradas 46 espécies em Alto do Comandante e 44 em Baixão da Cobra. Na primeira área, as famílias com maior número de espécies foram Apocynaceae, Bignoniaceae e Caesalpiniaceae (6 espécies), enquanto $65 \%$ das famílias estiveram representadas por uma única espécie. No Baixão da Cobra, destacaram-se, Caesalpiniaceae, Combretaceae (5 espécies), e Bignoniaceae (4), enquanto $60 \%$ das famílias estiveram representadas por uma única espécie. Das espécies de Bignoniaceae registradas, quatros foram lianas, em Alto do Comandante, enquanto em Baixão da Cobra foram apenas três. Em relação ao posicionamento das famílias quanto ao IVI, verificou-se em Alto do Comandante (Tab. 2), Apocynaceae $(17,23 \%)$, Combretaceae (16,82\%) e Caesalpiniaceae (12,69\%) e em Baixão da Cobra (Tab. 3), as mesmas famílias apresentaram maior IVI, entretanto Combretaceae apresentou (22,10\%), seguida de Apocynaceae 17,22\% e Caesalpiniaceae 12,71\%.

Em Alto do Comandante, a ordenação das espécies pelos seus valores de IVI seguiu a seguinte ordem, Casearia ulmifolia, Aspidosperma subincanum, Combretum leprosum e Bauhinia ungulata as quais, obtiveram os maiores IVI totais. A primeira posição para Casearia ulmifolia foi em 
Tabela 1. Lista das famílias e espécies amostradas na área do Complexo de Campo Maior, PI, com seus respectivos nomes vulgares, hábito e número de coletor (Ruth Raquel Soares de Farias e Clarissa Lopes - C). *Espécies amostráveis.

\begin{tabular}{|c|c|c|c|}
\hline Família/Espécie & Nome vulgar & Hábito & N. de coletor \\
\hline \multicolumn{4}{|l|}{ ANACARDIACEAE } \\
\hline 1. Anacardium occidentale L. & cajuí & árvore & 564 \\
\hline 2. Astronium fraxinifolium Schott. & gonçalo-alves & árvore & 345 \\
\hline \multicolumn{4}{|l|}{ ANNONACEAE } \\
\hline 3. Ephedranthus pisocarpus R.E. Fr. & cunduru-verdadeiro & árvore & $52 \mathrm{C}$ \\
\hline \multicolumn{4}{|l|}{ APOCYNACEAE } \\
\hline 4. Allamanda blanchetti DC. & расо-расо & arbst escandente & $397,419,425$ \\
\hline 5. Aspidosperma cuspa S.F. Blake ex Pittier & pereiro-branco & árvore & 410,509 \\
\hline 6. A. multiflorum A. DC. & piquiá-da-casca-grossa & árvore & 387,508 \\
\hline 7. A. pyrifolium Mart. & pereiro-preto & árvore & $361,378,409,412$ \\
\hline 8. A. subincanum Mart. & piquiá-da-casca-fina & árvore & 4620513,534 \\
\hline 9. Tabernaemontana hystrix Steud. & burra-leiteira & arvoreta & 396 \\
\hline \multicolumn{4}{|l|}{ BIGNONIACEAE } \\
\hline 10. Arrabidaea brachypoda (DC.) Bureau & bugi-da-folha-mole & liana & 538 \\
\hline 11. A. corallina (Jacq.) Sandwith & cipó verdadeiro & liana & 414,452 \\
\hline 12. A. cf. dispar Bureau ex K. Schum. & bugi-da-folha-dura & liana & 384,453 \\
\hline 13. Bignonia sp. & cipó-de-morcego & cipó & 574 \\
\hline 14. Cuspidaria sp.* & & liana & 411,430 \\
\hline 15. Jacaranda brasiliana (Lam.) Pers.* & caroba & árvore & 570 \\
\hline 16. Mansoa sp.* & & liana & 431, 435 \\
\hline 17. Melloa quadrivalvis (Jacq.) A.H. Gentry* & cipó-verdadeiro-roxo & cipó & 507 \\
\hline 18. Stizophyllum cf. perforatum (Cham.) Miers.* & & cipó & 413 \\
\hline 19. Tabebuia impetiginosa (Mart. ex DC.) Standl. & pau-d'arco-roxo & árvore & 561 \\
\hline 20. T. serratifolia G. Nicholson & pau-d’arco-amarelo & árvore & 571 \\
\hline \multicolumn{4}{|l|}{ BIXACEAE } \\
\hline 21. Cochlospermum cf. vitifolium (Willd.) Spreng. & algodão-bravo & arvoreta & 560 \\
\hline \multicolumn{4}{|l|}{ BORAGINACEAE } \\
\hline 22. Cordia rufescens A. DC. & grão-de-galo & arbusto & 448,500 \\
\hline \multicolumn{4}{|l|}{ CACTACEAE } \\
\hline 23. Cereus jamacaru DC. & mandacaru & arbusto & 521,522 \\
\hline \multicolumn{4}{|l|}{ CAESALPINIACEAE } \\
\hline 24. Bauhinia dubia G. Don & mororó-rasteiro & arbusto & 403, 463 \\
\hline 25. B. pulchella Benth. & mororó-de-bode & arbusto & 354, 386, 408 \\
\hline 26. B. ungulata $\mathrm{L}$. & mororó-verdadeiro & arbusto & 347,401 \\
\hline 27. Caesalpinia bracteosa Tul. & milombe & árvore & 518 \\
\hline 28. C. ferrea Mart. ex Tul. & pau-ferro & arvoreta & 516 \\
\hline 29. Copaifera coriacea Mart.* & podoizinho & árvore & 50C, 152C \\
\hline 30. Copaifera sp.* & podói & árvore & 567 \\
\hline 31. Hymenaea courbaril L. & jatobá-da-mata & árvore & 434 \\
\hline 32. Martiodendron mediterraneum (Mart. ex Benth.) Koeppen. & catinga-de-porco & árvore & 519 \\
\hline 33. Senna acuruensis (Benth.) Irwin \& Barneby & besouro & arbusto & 334, 343, 398 \\
\hline \multicolumn{4}{|l|}{ COMBRETACEAE } \\
\hline 34. Buchenavia capitata (Vahl) Mart. & mirindiba & árvore & 364,540 \\
\hline 35. Combretum duarteanum Cambess. & rama-branca & arbusto & $348,403,427$ \\
\hline 36. C. lanceolatum Pohl. & cipó-de-remela & cipó & 546,550 \\
\hline 37. C. leprosum Mart. & mufumbo-branco & arbusto & 499 \\
\hline 38. C. mellifluum Eichler & farinha-seca & arbusto & 355,475 \\
\hline 39. Terminalia actinophylla Mart. & chapada & árvore & 338, 432 \\
\hline \multicolumn{4}{|l|}{ DILLENIACEAE } \\
\hline 40. Curatella americana L. & lixeira & arvoreta & 553 \\
\hline \multicolumn{4}{|l|}{ EUPHORBIACEAE } \\
\hline 41. Croton campestris L. & marmeleiro & arbusto & 423 \\
\hline \multicolumn{4}{|l|}{ FABACEAE } \\
\hline 42. Amburana cearensis (Allemão) A.C. Sm & imburana-de-cheiro & árvore & 555 \\
\hline 43. Luetzelburgia auriculata Ducke & pau-mocó & árvore & 565 \\
\hline 44. Machaerium acutifolium Vogel & violete & árvore & 515,541 \\
\hline
\end{tabular}


Tabela 1 (continuação)

\begin{tabular}{|c|c|c|c|}
\hline Família/Espécie & Nome vulgar & Hábito & N. de coletor \\
\hline \multicolumn{4}{|l|}{ FLACOURTIACEAE } \\
\hline 45. Casearia ulmifolia Vahl ex Vent. & cunduru-miúdo & arbusto & $357,449,450$ \\
\hline \multicolumn{4}{|l|}{ MALPIGHIACEAE } \\
\hline 46. Banisteriopsis sp. & cipó-mole & liana & 346, 351, 374 \\
\hline 47. Byrsonima cf. sericea DC. & murici & arvoreta & $369,373,382$ \\
\hline \multicolumn{4}{|l|}{ MIMOSACEAE } \\
\hline 48. Mimosa caesalpinifolia Benth. & unha-de-gato & arbusto & 87C \\
\hline 49. M. cf. nothopteris Barneby & jurema-branca & arvoreta & 493 \\
\hline \multicolumn{4}{|l|}{ MORACEAE } \\
\hline 50. Brosimum gaudichaudii Trécul & inharé & árvore & 389 \\
\hline \multicolumn{4}{|l|}{ MYRTACEAE } \\
\hline 51. Psidium myrsinites DC. & muta-brava & arvoreta & $30 \mathrm{C}$ \\
\hline \multicolumn{4}{|l|}{ OCHNACEAE } \\
\hline 52. Ouratea cearensis (Tiegh.) Sastre* & merim-brabo & árvore & 407 \\
\hline \multicolumn{4}{|l|}{ OLACACEAE } \\
\hline 53. Ximenia americana L. & ameixa & arbusto & 372 \\
\hline \multicolumn{4}{|l|}{ OPILIACEAE } \\
\hline 54. Agonandra brasiliensis Miers & pau-marfim & árvore & 328 \\
\hline \multicolumn{4}{|l|}{ RUBIACEAE } \\
\hline 55. Alibertia edulis (L.C. Rich.) A. Rich. ex DC. & marmelada-roxa & arvoreta & 557 \\
\hline 56. Chomelia obtusa Cham. \& Schltdt. & pustemeira & arbusto & 390,460 \\
\hline 57. Guettarda virbunoides Cham. \& Schltdl. & angélica & arvoreta & 332, 424 \\
\hline 58. Randia armata (Sw.) DC.* & quina-quina & arbusto & 399 \\
\hline 59. Tocoyena hispidula Standl. & angeliquinha & arbusto & $358,420,503$ \\
\hline \multicolumn{4}{|l|}{ SAPINDACEAE } \\
\hline 60. Magonia pubescens A. St.-Hil. & tingui-de-bola & árvore & 572 \\
\hline \multicolumn{4}{|l|}{ SAPOTACEAE } \\
\hline 61. Pouteria sp. & pitomba-de-leite & árvore & $24 \mathrm{C}$ \\
\hline \multicolumn{4}{|l|}{ SIMAROUBACEAE } \\
\hline 62. Simarouba versicolor A. St.-Hil. & paraíba & árvore & 333 \\
\hline \multicolumn{4}{|l|}{ STERCULIACEAE } \\
\hline 63. Helicteres heptandra L.B. Sm. & sacatrapo & arbusto & 340,400 \\
\hline \multicolumn{4}{|l|}{ TILIACEAE } \\
\hline 64. Luehea speciosa Willd. & açoita-cavalo & árvore & 573 \\
\hline \multicolumn{4}{|l|}{ VERBENACEAE } \\
\hline 65. Vitex cymosa Bert. ex Spreng. & mama-cachorra & árvore & 04C, 23C \\
\hline \multicolumn{4}{|l|}{ VOCHYSIACEAE } \\
\hline 66. Callisthene fasciculata Mart. & capitão-de-campo & arvoreta & 330,341 \\
\hline 67. Qualea grandiflora Mart. & pau-terra-da-folha-larga & árvore & 433 \\
\hline 68. Q. parviflora Mart. & pau-terra-da-folha-miúda & árvore & 380 \\
\hline
\end{tabular}

conseqüência dos três parâmetros relativos, caracterizando a mesma como de ampla distribuição na área de estudo. Apenas as três espécies de maiores IVIs contribuíram com os maiores IVC (Tab. 4).

Na segunda área, a espécie de maior importância foi Aspidosperma subincanum (Tab. 5) em conseqüência dos valores dos três parâmetros relativos. Depois seguiram-se as espécies, Combretum mellifluum, Bauhinia pulchella e Buchenavia capitata. Neste caso, as quatro espécies com maiores valores de IVI também apresentaram maiores IVC.
No Alto do Comandante, nove espécies representaram $64 \%$ do número total de indivíduos, sendo consideradas dominantes na taxocenose, destacando-se, Combretum leprosum (10,5\%) e Casearia ulmifolia $(9,75 \%)$ e as demais apresentaram valores abaixo de $8 \%$. No Baixão da Cobra, de forma semelhante, nove espécies corresponderam a 65,25\% do total de indivíduos, com destaque para B. pulchella $(13,75 \%)$ e A. subincanum (13,25\%).

Na Tab. 6 apresenta-se os valores de alguns parâmetros fisionômicos encontrados nas áreas estudadas e em 26 levantamentos realizados em 
Tabela 2. Famílias e seus parâmetros fitossociológicos em ordem decrescente da porcentagem do índice de valor de importância (IVI), Alto do Comandante, Campo Maior, PI. N. - número de indivíduos/espécies; DR - \% densidade relativa; DoR - \% dominância relativa; FR - \% freqüência relativa; IVI - \% índice do valor de importância; IVC - \% índice do valor de cobertura.

\begin{tabular}{|c|c|c|c|c|c|c|c|}
\hline Famílias & N. ind. & Nspp & DR & DoR & FR & IVI & IVC \\
\hline Apocynaceae & 75 & 6 & 19,25 & 14,59 & 17,85 & 17,23 & 16,92 \\
\hline Combretaceae & 68 & 5 & 17,00 & 18,99 & 14,48 & 16,82 & 17,99 \\
\hline Ceasalpiniaceae & 57 & 6 & 14,25 & 10,68 & 13,13 & 12,69 & 12,46 \\
\hline Flacourtiaceae & 39 & 1 & 9,75 & 8,53 & 10,44 & 9,57 & 9,14 \\
\hline Vochysiaceae & 36 & 3 & 9,00 & 6,58 & 10,10 & 8,56 & 7,79 \\
\hline Bignoniaceae & 23 & 6 & 5,75 & 5,45 & 7,07 & 6,09 & 5,60 \\
\hline Malpighiaceae & 24 & 1 & 6,00 & 4,69 & 5,72 & 5,47 & 5,34 \\
\hline Sterculiaceae & 25 & 1 & 6,25 & 1,23 & 6,73 & 4,74 & 3,74 \\
\hline Sapotaceae & 1 & 1 & 0,25 & 11,54 & 0,34 & 4,04 & 5,90 \\
\hline Dilleniaceae & 10 & 1 & 2,50 & 4,03 & 2,69 & 3,07 & 3,26 \\
\hline Fabaceae & 8 & 3 & 2,00 & 3,58 & 2,69 & 2,76 & 2,79 \\
\hline Rubiaceae & 13 & 3 & 3,25 & 1,47 & 3,37 & 2,70 & 2,36 \\
\hline Annonaceae & 2 & 1 & 0,50 & 3,44 & 0,67 & 1,54 & 1,97 \\
\hline Olacaceae & 7 & 1 & 1,75 & 0,45 & 1,68 & 1,29 & 1,10 \\
\hline Anacardiaceae & 2 & 2 & 0,50 & 2,64 & 0,67 & 1,27 & 1,57 \\
\hline Euphorbiaceae & 4 & 1 & 1,00 & 0,31 & 1,01 & 0,57 & 0,66 \\
\hline Moraceae & 1 & 1 & 0,25 & 0,82 & 0,34 & 0,47 & 0,54 \\
\hline Sapindaceae & 1 & 1 & 0,25 & 0,60 & 0,34 & 0,40 & 0,43 \\
\hline Opiliaceae & 1 & 1 & 0,25 & 0,35 & 0,34 & 0,31 & 0,30 \\
\hline Cactaceae & 1 & 1 & 0,25 & 0,03 & 0,34 & 0,21 & 0,14 \\
\hline
\end{tabular}

Tabela 3. Famílias e seus parâmetros fitossociológicos em ordem decrescente do índice do valor de importância (IVI) no Baixão da Cobra, Campo Maior, PI. N. - número de indivíduos/espécies; DR - \% densidade relativa; DoR - \% dominância relativa; FR - \% freqüência relativa; IVI - \% índice do valor de importância; IVC - \% índice do valor de cobertura.

\begin{tabular}{|c|c|c|c|c|c|c|c|}
\hline Famílias & N. ind. & Nspp & DR & DoR & FR & IVI & IVC \\
\hline Combretaceae & 58 & 5 & 14,50 & 14,50 & 12,66 & 22,10 & 26,82 \\
\hline Apocynaceae & 68 & 4 & 17,00 & 17,00 & 14,61 & 17,22 & 18,52 \\
\hline Caesalpiniaceae & 68 & 5 & 17,00 & 17,00 & 15,91 & 12,71 & 11,11 \\
\hline Sterculiaceae & 28 & 1 & 7,00 & 7,00 & 8,44 & 5,98 & 4,74 \\
\hline Rubiaceae & 28 & 3 & 7,00 & 7,00 & 8,12 & 5,87 & 4,74 \\
\hline Vochysiaceae & 27 & 3 & 6,75 & 6,75 & 6,17 & 5,78 & 5,58 \\
\hline Bignoniaceae & 23 & 4 & 5,75 & 5,75 & 6,49 & 5,48 & 4,97 \\
\hline Malpighiaceae & 21 & 2 & 5,25 & 5,25 & 4,87 & 4,66 & 4,55 \\
\hline Euphorbiaceae & 18 & 1 & 4,50 & 4,50 & 4,22 & 3,86 & 3,67 \\
\hline Flacourtiaceae & 17 & 1 & 4,25 & 4,25 & 4,87 & 3,60 & 2,96 \\
\hline Fabaceae & 12 & 2 & 3,00 & 3,00 & 3,90 & 3,20 & 2,85 \\
\hline Mimosaceaee & 8 & 2 & 2,00 & 2,00 & 2,27 & 2,09 & 1,99 \\
\hline Moraceae & 3 & 1 & 0,75 & 0,75 & 0,97 & 1,87 & 2,32 \\
\hline Dilleniaceae & 5 & 1 & 1,25 & 1,25 & 1,62 & 1,17 & 0,95 \\
\hline Opiliaceae & 3 & 1 & 0,75 & 0,75 & 0,65 & 1,01 & 1,19 \\
\hline Tiliaceae & 3 & 1 & 0,75 & 0,75 & 0,97 & 0,79 & 0,70 \\
\hline Olacaceae & 2 & 1 & 0,50 & 0,50 & 0,65 & 0,70 & 0,72 \\
\hline Annonaceae & 3 & 1 & 0,75 & 0,75 & 0,97 & 0,66 & 0,50 \\
\hline Myrtaceae & 1 & 1 & 0,25 & 0,25 & 0,32 & 0,37 & 0,39 \\
\hline Sapindaceae & 1 & 1 & 0,25 & 0,25 & 0,32 & 0,29 & 0,28 \\
\hline Verbenaceae & 1 & 1 & 0,25 & 0,25 & 0,32 & 0,21 & 0,15 \\
\hline Bixaceae & 1 & 1 & 0,25 & 0,25 & 0,32 & 0,20 & 0,14 \\
\hline Boraginaceae & 1 & 1 & 0,25 & 0,25 & 0,32 & 0,20 & 0,14 \\
\hline
\end{tabular}


Tabela 4. Espécies e seus parâmetros fitossociológicos em ordem decrescente da porcentagem do índice do valor de importância (IVI) no Alto do Comandante, Campo Maior, PI. N. - número de indivíduos; DR - \% densidade relativa; DoR - \% dominância relativa; FR - \% freqüência relativa; IVI - \% índice do valor de importância; IVC - \% índice do valor de cobertura.

\begin{tabular}{|c|c|c|c|c|c|c|}
\hline Famílias & N. ind. & DR & DoR & FR & IVI & IVC \\
\hline Casearia ulmifolia & 39 & 9,75 & 8,53 & 9,63 & 27,91 & 18,28 \\
\hline Aspidosperma subincanum & 32 & 8,00 & 10,25 & 7,76 & 26,01 & 18,25 \\
\hline Combretum leprosum & 42 & 10,50 & 4,70 & 9,63 & 24,83 & 15,20 \\
\hline Bauhinia ungulata & 32 & 8,00 & 1,82 & 7,45 & 17,27 & 9,82 \\
\hline Aspidosperma multiflorum & 29 & 7,25 & 3,71 & 6,21 & 17,27 & 10,96 \\
\hline Banisteriopsis sp. & 24 & 6,00 & 4,69 & 5,28 & 15,97 & 10,69 \\
\hline Helicteres heptandra & 25 & 6,25 & 1,23 & 6,21 & 13,69 & 7,48 \\
\hline Combretum duarteanum & 14 & 3,50 & 6,21 & 3,73 & 13,43 & 9,71 \\
\hline Qualea grandiflora & 19 & 4,75 & 3,47 & 4,66 & 12,88 & 8,22 \\
\hline Pouteria sp. & 1 & 0,25 & 11,54 & 0,31 & 12,10 & 11,79 \\
\hline Buchenavia capitata & 6 & 1,50 & 7,26 & 1,55 & 10,31 & 8,76 \\
\hline Curatella americana & 10 & 2,50 & 4,03 & 2,48 & 9,01 & 6,53 \\
\hline Senna acuruensis & 10 & 2,50 & 2,67 & 2,48 & 7,65 & 5,17 \\
\hline Qualea parviflora & 10 & 2,50 & 1,36 & 3,11 & 6,97 & 3,86 \\
\hline Arrabidaea brachypoda & 10 & 2,50 & 1,17 & 2,80 & 6,46 & 3,67 \\
\hline Guettarda virbunoides & 9 & 2,25 & 0,94 & 2,48 & 5,67 & 3,19 \\
\hline Bauhinia pulchella & 9 & 2,25 & 0,66 & 2,48 & 5,39 & 2,91 \\
\hline Callisthene fasciculata & 7 & 1,75 & 1,74 & 1,86 & 5,36 & 3,49 \\
\hline Aspidosperma cuspa & 9 & 2,25 & 0,45 & 2,48 & 5,19 & 2,70 \\
\hline Hymenaea courbaril & 1 & 0,25 & 4,11 & 0,31 & 4,67 & 4,36 \\
\hline Ephedranthus pisocarpus & 2 & 0,50 & 3,44 & 0,62 & 4,56 & 3,94 \\
\hline Arrabidaea dispar & 6 & 1,50 & 0,78 & 1,55 & 3,84 & 2,28 \\
\hline Ximenia americana & 7 & 1,75 & 0,45 & 1,55 & 3,75 & 2,20 \\
\hline Luetzelburgia auriculata & 3 & 0,75 & 1,80 & 0,93 & 3,49 & 2,55 \\
\hline Combretum mellifluum & 5 & 1,25 & 0,69 & 1,24 & 3,18 & 1,94 \\
\hline Anacardium occidentale & 1 & 0,25 & 2,51 & 0,31 & 3,08 & 2,76 \\
\hline Tabebuia serratifolia & 4 & 1,00 & 0,78 & 1,24 & 3,03 & 1,78 \\
\hline Tabebuia impetiginosa & 1 & 0,25 & 2,40 & 0,31 & 2,96 & 2,65 \\
\hline Macherium acutifolium & 3 & 0,75 & 0,93 & 0,93 & 2,61 & 1,68 \\
\hline Aspidosperma pyrifolium & 4 & 1,00 & 0,10 & 1,24 & 2,34 & 1,10 \\
\hline Corton campestris & 4 & 1,00 & 0,31 & 0,93 & 2,24 & 1,31 \\
\hline Bauhinia dubia & 4 & 1,00 & 0,22 & 0,93 & 2,15 & 1,22 \\
\hline Amburana cearensis & 2 & 0,50 & 0,85 & 0,62 & 1,97 & 1,35 \\
\hline Caesalpinia bracteosa & 1 & 0,25 & 1,20 & 0,31 & 1,76 & 1,45 \\
\hline Chomelia obtusa & 1 & 0,75 & 0,09 & 0,62 & 1,46 & 0,84 \\
\hline Brosimum gaudichaudii & 3 & 0,25 & 0,82 & 0,31 & 1,38 & 1,07 \\
\hline Tabernaemontana hystrix & 1 & 0,50 & 0,06 & 0,62 & 1,18 & 0,56 \\
\hline Magonia pubescens & 3 & 0,25 & 0,60 & 0,31 & 1,16 & 0,85 \\
\hline Alibertia edulis & 1 & 0,25 & 0,45 & 0,31 & 1,01 & 0,70 \\
\hline Agonandra brasiliensis & 2 & 0,25 & 0,35 & 0,31 & 0,91 & 0,60 \\
\hline Bignonia sp. & 1 & 0,25 & 0,19 & 0,31 & 0,76 & 0,44 \\
\hline Combretum lanceolatum & 1 & 0,25 & 0,13 & 0,31 & 0,69 & 0,8 \\
\hline Astronium fraxinifolium & 1 & 0,25 & 0,12 & 0,31 & 0,68 & 0,37 \\
\hline Arrabidaea corallina & 1 & 0,25 & 0,12 & 0,31 & 0,68 & 0,37 \\
\hline Cereus jamacaru & 1 & 0,25 & 0,03 & 0,31 & 059 & 0,28 \\
\hline Allamanda blanchetti & 1 & 0,25 & 0,02 & 0,31 & 0,58 & 0,27 \\
\hline
\end{tabular}

diversos tipos vegetacionais do Nordeste.

Os valores para a densidade total de Alto do Comandante e Baixão da Cobra, foram de 2.730 e 2.799ind ha ${ }^{-1}$, sendo inferiores aos da maioria dos trabalhos consultados, exceto nos de M.J.N. Rodal (dados não publicados), Rodal et al. (1998) e Figueirêdo et al. (2000), todas localizadas no Estado de Pernambuco. As áreas basais foram de 38,22 e $38,58 \mathrm{~m}^{2} \mathrm{ha}^{-1}$ para Alto do Comandante e Baixão da Cobra, respectivamente, neste caso, sendo superiores a quase todos os levantamentos analisados, exceto por uma área de carrasco de Araújo et al. (1998). 
Tabela 5. Espécies e seus parâmetros fitossociológicos em ordem decrescente do índice do valor de importância (IVI) no Baixão da Cobra, Campo Maior, PI. N. - número de indivíduos; DR - \% densidade relativa; DoR - \% dominância relativa; FR - \% freqüência relativa; IVI - \% índice do valor de importância; IVC - \% índice do valor de cobertura.

\begin{tabular}{|c|c|c|c|c|c|c|}
\hline Famílias & N. ind. & DR & DoR & FR & IVI & IVC \\
\hline Aspidosperma subincanum & 53 & 13,25 & 11,25 & 10,74 & 35,23 & 24,50 \\
\hline Combretum mellifluum & 36 & 9,00 & 13,54 & 7,36 & 29,90 & 22,54 \\
\hline Bauhinia pulchela & 55 & 13,75 & 2,44 & 12,58 & 28,77 & 16,19 \\
\hline Bouchenavia capitata & 8 & 2,00 & 14,55 & 2,15 & 18,69 & 16,55 \\
\hline Helicteres heptandra & 28 & 7,00 & 2,48 & 7,98 & 17,46 & 9,48 \\
\hline Aspidosperma multiflorum & 13 & 3,25 & 8,61 & 3,68 & 15,54 & 11,86 \\
\hline Guettarda virbunoides & 25 & 6,25 & 2,32 & 6,75 & 15,32 & 8,57 \\
\hline Banisteriopsis sp. & 20 & 5,00 & 3,37 & 4,29 & 12,67 & 8,37 \\
\hline Croton campestris & 18 & 4,50 & 2,84 & 3,99 & 11,33 & 7,34 \\
\hline Terminalia actinophylla & 2 & 0,50 & 9,62 & 0,61 & 10,73 & 10,12 \\
\hline Casearia ulmifolia & 17 & 4,25 & 1,67 & 4,60 & 10,52 & 5,92 \\
\hline Arrabidaea dispar & 12 & 3,00 & 2,94 & 3,07 & 9,00 & 5,94 \\
\hline Qualea parviflora & 12 & 3,00 & 3,20 & 2,76 & 8,96 & 6,20 \\
\hline Macherium acutifolium & 10 & 2,50 & 0,99 & 3,07 & 6,56 & 3,49 \\
\hline Qualea grandiflora & 11 & 2,75 & 0,65 & 3,07 & 6,46 & 3,40 \\
\hline Combretum leprosum & 10 & 2,50 & 1,34 & 2,45 & 6,29 & 3,84 \\
\hline Brosimum gaudichaudii & 3 & 0,75 & 3,89 & 0,92 & 5,56 & 4,64 \\
\hline Mimosa caesalpiniifolia & 7 & 1,75 & 1,92 & 1,84 & 5,51 & 3,67 \\
\hline Tabebuia serratifolia & 8 & 2,00 & 0,75 & 2,45 & 5,20 & 2,75 \\
\hline Bauhinia ungulata & 8 & 2,00 & 0,59 & 2,45 & 5,05 & 2,59 \\
\hline Curatella americana & 5 & 1,25 & 0,64 & 1,53 & 3,43 & 1,89 \\
\hline Agonandra brasiliensis & 3 & 0,75 & 1,62 & 0,61 & 2,99 & 2,37 \\
\hline Luetzelburgia auriculata & 2 & 0,50 & 1,70 & 0,61 & 2,81 & 2,20 \\
\hline Callisthene fasciculata & 4 & 1,00 & 0,56 & 1,23 & 2,78 & 1,56 \\
\hline Hymenaea courbaril & 2 & 0,50 & 1,55 & 0,61 & 2,66 & 2,05 \\
\hline Luehea speciosa & 3 & 0,75 & 0,65 & 0,92 & 2,32 & 1,40 \\
\hline Ximenia americana & 2 & 0,50 & 0,95 & 0,61 & 2,06 & 1,47 \\
\hline Ephedranthus pisocarpus & 3 & 0,75 & 0,26 & 0,92 & 1,93 & 1,01 \\
\hline Arrabidaea corrallina & 2 & 0,50 & 0,16 & 0,61 & 1,28 & 0,66 \\
\hline Combretum duarteanum & 2 & 0,50 & 0,11 & 0,61 & 1,22 & 0,61 \\
\hline Tocoyena hispidula & 2 & 0,50 & 0,10 & 0,61 & 1,21 & 0,60 \\
\hline Senna acuruensis & 2 & 0,50 & 0,07 & 0,61 & 1,19 & 0,57 \\
\hline Martiodendron mediterraneum & 1 & 0,25 & 0,57 & 0,31 & 1,13 & 0,82 \\
\hline Psidium myrsinitis & 1 & 0,25 & 0,54 & 0,31 & 1,09 & 0,79 \\
\hline Byrsonima cf. sericea & 1 & 0,25 & 0,49 & 0,31 & 1,04 & 0,74 \\
\hline Arrabidaea brachypoda & 1 & 0,25 & 0,35 & 0,31 & 0,90 & 0,60 \\
\hline Magonia pubescens & 1 & 0,25 & 0,31 & 0,31 & 0,86 & 0,56 \\
\hline Aspidosperma cuspa & 1 & 0,25 & 0,16 & 0,31 & 0,71 & 0,41 \\
\hline Mimosa cf. nothopteris & 1 & 0,25 & 0,07 & 0,31 & 0,63 & 0,32 \\
\hline Chomelia obtusa & 1 & 0,25 & 0,06 & 0,31 & 0,62 & 0,31 \\
\hline Vytex cimosa & 1 & 0,25 & 0,05 & 0,31 & 0,60 & 0,30 \\
\hline Cordia rufescens & 1 & 0,25 & 0,04 & 0,31 & 0,59 & 0,29 \\
\hline Cochlospermum cf. vitifolium & 1 & 0,25 & 0,04 & 0,31 & 0,59 & 0,29 \\
\hline Allamada blanchetii & 1 & 0,25 & 0,03 & 0,31 & 0,59 & 0,28 \\
\hline
\end{tabular}

O índice de Shannon (H') foi de 3,20nats ind. ${ }^{-1}$ para Alto do Comandante e 3,09nats ind. ${ }^{-1}$ para o Baixão da Cobra, que possuem uma alta diversidade de espécies, sendo superior as encontradas na Caatinga, Cerrado e em algumas áreas do Carrasco do Nordeste. Estes resultados devem-se provavelmente ao método de amostragem, ao tamanho da área amostrada e, ainda devido as regiões ecotonais, corresponderem também, a áreas onde processos de especiação ocorrem com maior freqüência.

O índice de riqueza das espécies, 7,68nats esp $^{-1}$ para Alto do Comandante e 7,34nats esp ${ }^{-1}$ para Baixão da Cobra também foi considerado alto, sendo semelhantes aos valores de F.G. Alcoforado Filho 


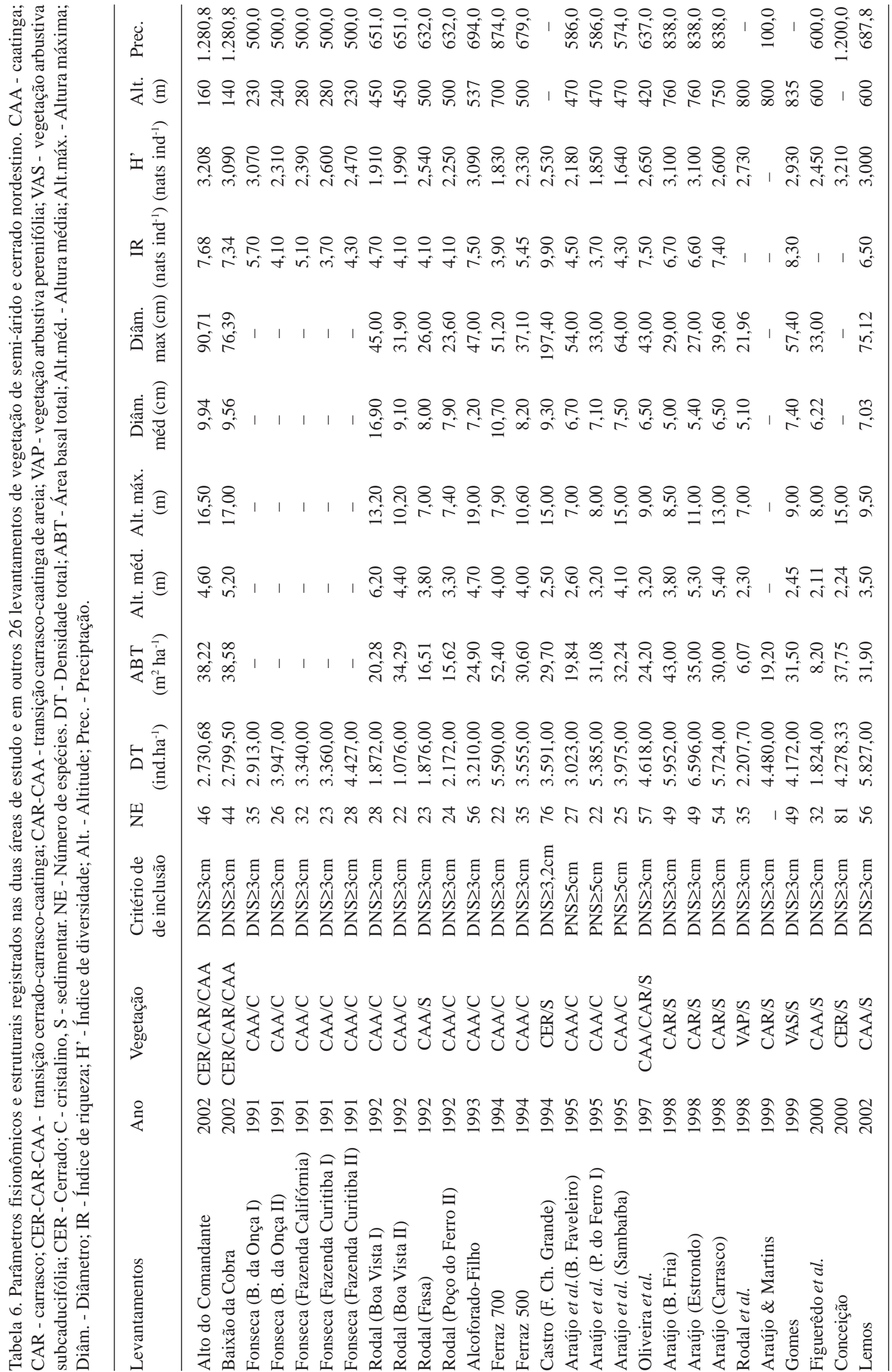


(dados não publicados) em área de caatinga, Oliveira et al. (1997) em transição caatinga de areia-carrasco, de Araújo et al. (1998) no carrasco, no entanto foram inferiores aos valores encontrados por A.P.S. Gomes (dados não publicados), com 8,3nats esp ${ }^{-1}$, em vegetação arbustiva subcaducifólia no município de Buíque, Pernambuco.

As alturas médias e máximas foram de 4,60 e 16,50m em Alto do Comandante e 5,20 e 17,0m em Baixão da Cobra e os diâmetros médios e máximos 9,94 e 90,71cm em Alto do Comandante e 9,56 e 76,39cm no Baixão da Cobra. Quando comparados a levantamentos realizados em outros tipos vegetacionais, a altura média foi similar às duas áreas de carrasco estudadas por Araújo et al. (1998), superior a todos os outros, e inferior a uma área de caatinga do cristalino estudada por M.J.N. Rodal (dados não publicados). A altura máxima foi superada apenas em uma área de caatinga do cristalino (F.G. Alcoforado Filho, dados não publicados). Os valores para os diâmetros médios, por sua vez, foram superados apenas em estudos realizados por M.J.N. Rodal (dados não publicados), e E.M.N. Ferraz (dados não publicados) em Serra Talhada, a 700m de altitude, e o diâmetro máximo apenas nas pesquisas de Castro (1994) com 197,4cm em uma área de cerrado.

Entre a altura mínima de $1 \mathrm{~m}$ e a máxima de $17 \mathrm{~m}$ em Alto do Comandante e em Baixão da Cobra foram definidas 16 e 17 classes, respectivamente (Fig. 2). As classes com maior número de indivíduos em Alto do Comandante e no Baixão da Cobra foram a segunda, terceira, quarta e quinta, o que corresponde a $63,75 \%$ em Alto do Comandante e 68,75\% em Baixão da Cobra. As espécies que apresentaram maior altura individual foram Tabebuia impetiginosa e Buchenavia capitata, em Alto do Comandante e Luetzelburgia auriculata no Baixão da Cobra.

Em relação às classes de diâmetro, Alto do Comandante e Baixão da Cobra apresentaram 30 e 25 classes (Fig. 3), respectivamente, tendo as duas primeiras destacado-se com 255 indivíduos, perfazendo 63,75\% do total em Alto do Comandante, e 275 (68,75\%) do total de indivíduos amostrados no Baixão da Cobra. As espécies que apresentaram maiores diâmetros foram: Pouteria sp., em Alto do Comandante e Terminalia actinophylla, no Baixão da Cobra.

As populações amostradas nas duas áreas estudadas formaram dois estratos (Fig. 4 e 5): em Alto do Comandante, o estrato superior incluiu 38 espécies, sendo Tabebuia impetiginosa e Buchenavia capitata as duas emergentes. O estrato inferior é composto pelas espécies, Croton campestris, Bauhinia dubia, Aspidosperma pyrifolium, Chomelia obtusa, Cereus jamacaru e Allamanda blanchetti; no Baixão da Cobbra, o estrato superior esteve representado por 37 espécies, tendo Luetzelburgia auriculata como

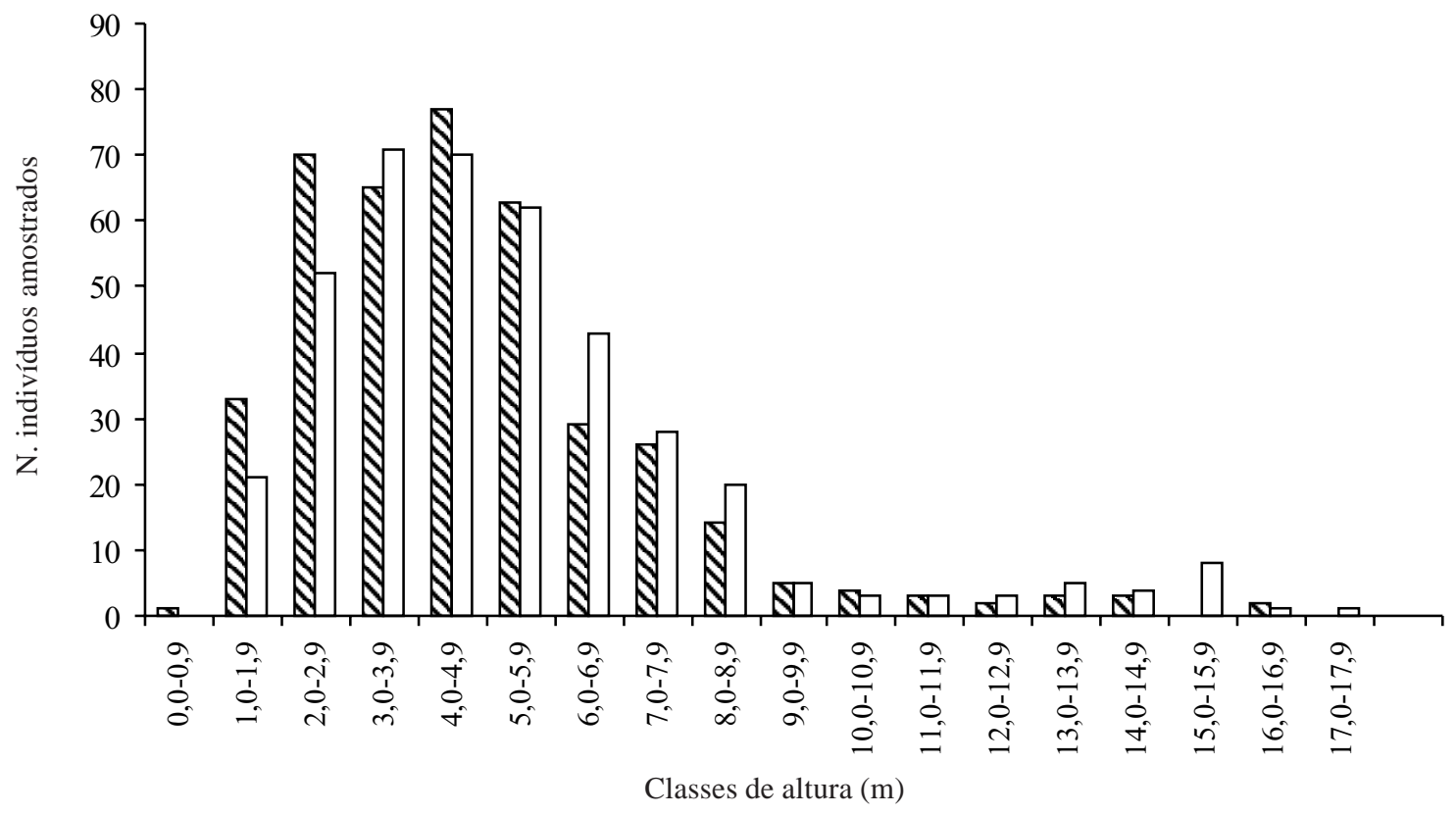

Figura 2. Distribuição do número de indivíduos por classes de altura, a intervalo fixo de $1 \mathrm{~m}$, fechado à esquerda e aberto à direita. $\square=$ Alto do comandante; $\square$ = Baixão da Cobra. 


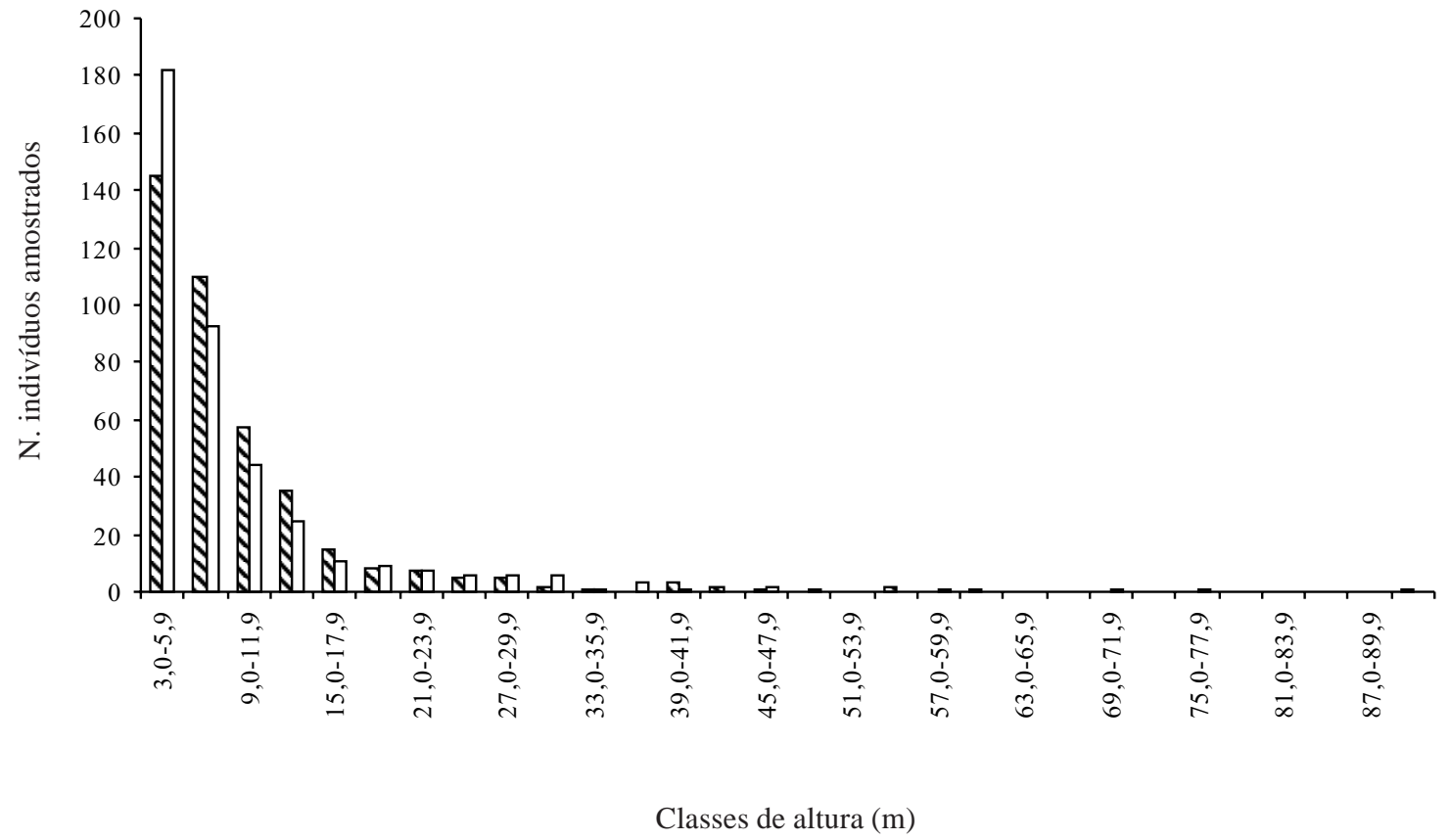

Figura 3. Distribuição do número de indivíduos por classes de diâmetro, a intervalo fixo de $3 \mathrm{~cm}$, fechado à esquerda e aberto à direita. $\square$ = Alto do comandante; $\square$ = Baixão da Cobra.

emergente e o inferior, com sete espécies, Combretum duarteanum, Senna acuruensis, Vitex cymosa, C. obtusa, Cordia rufescens, Allamanda blanchetti e Tocoyena hispidula.

A sinúsia das áreas estudadas foi predominantemente microfanerofítica perfazendo $81,75 \%$, dos indivíduos em Alto do Comandante e 79\% em Baixão da Cobra. Para representar as formas de vida das espécies, considerou-se a altura máxima, onde destacaram-se as microfanerofítas e mesofanerófitas (24 e 21 espécies) em Alto do Comandante e em Baixão do Cobra (23 e 20), respectivamente. O número de espécies mesofanerófitas foi superior a dos trabalhos realizados para outros tipos vegetacionais como os de M.J.N. Rodal (dados não publicados); F.G. Alcoforado Filho (dados não publicados); E.M.N. Ferraz (dados não publicados); Oliveira et al. (1997) e Rodal et al. (1998).

As Fig. 6 a 9 representam quatro dos dez perfis esquemáticos da vegetação amostrada. Observa-se que as áreas em geral são fechadas, com uma presença marcante de cipós, pouco estrato herbáceo, enquanto o estrato arbóreo de médio porte, não forma um dossel fechado e apresentam poucas espécies emergentes. Mesmo esquematicamente, pode-se notar que as áreas possuem fisionomia distinta, não se enquadrando a outras já analisadas. Isto pode ser facilmente comprovado nas mudanças visíveis de um perfil para outro, principalmente, considerando o fato de ser um conjunto de perfis referente à vegetação de uma mesma área.

Ao se comparar as espécies listadas neste trabalho, com as encontradas em outros levantamentos de vários tipos vegetacionais do Nordeste, observou-se que 18 espécies foram exclusivas às duas áreas estudadas, sendo nove espécies comuns ao Alto do Comandante e Baixão da Cobra, Aspidosperma cuspa, Bauhinia pulchella, Bauhinia ungulata, Callisthene fasciculata, Casearia ulmifolia, Combretum duarteanum, Croton campestris, Guettarda virbunoides e Helicteres heptandra; três presentes apenas em Alto do Comandante, Caesalpinia bracteosa, Combretum lanceolatum e Tabernaemontana hystrix e seis em Baixão da Cobra, Luehea speciosa, Martiodendron mediterraneum, Mimosa caesalpiniifolia, Terminalia actinophylla, Tocoyena hispidula e Cochlospermum cf. vitifolium. Destas, algumas como Aspidosperma cuspa, C. campestris e $M$. caesalpinifolia são consideradas endêmicas da caatinga segundo Giulietti et al. (2002).

Com a análise de agrupamento, verificou-se que o índice de Jaccard fez uma melhor formação de dois grupos florísticos (Fig. 10): A, que evidenciou a vegetação de caatinga instalada no cristalino como M.R. Fonseca (dados não publicados), M.J.N. Rodal (dados não publicados), F.G. Alcoforado Filho (dados 


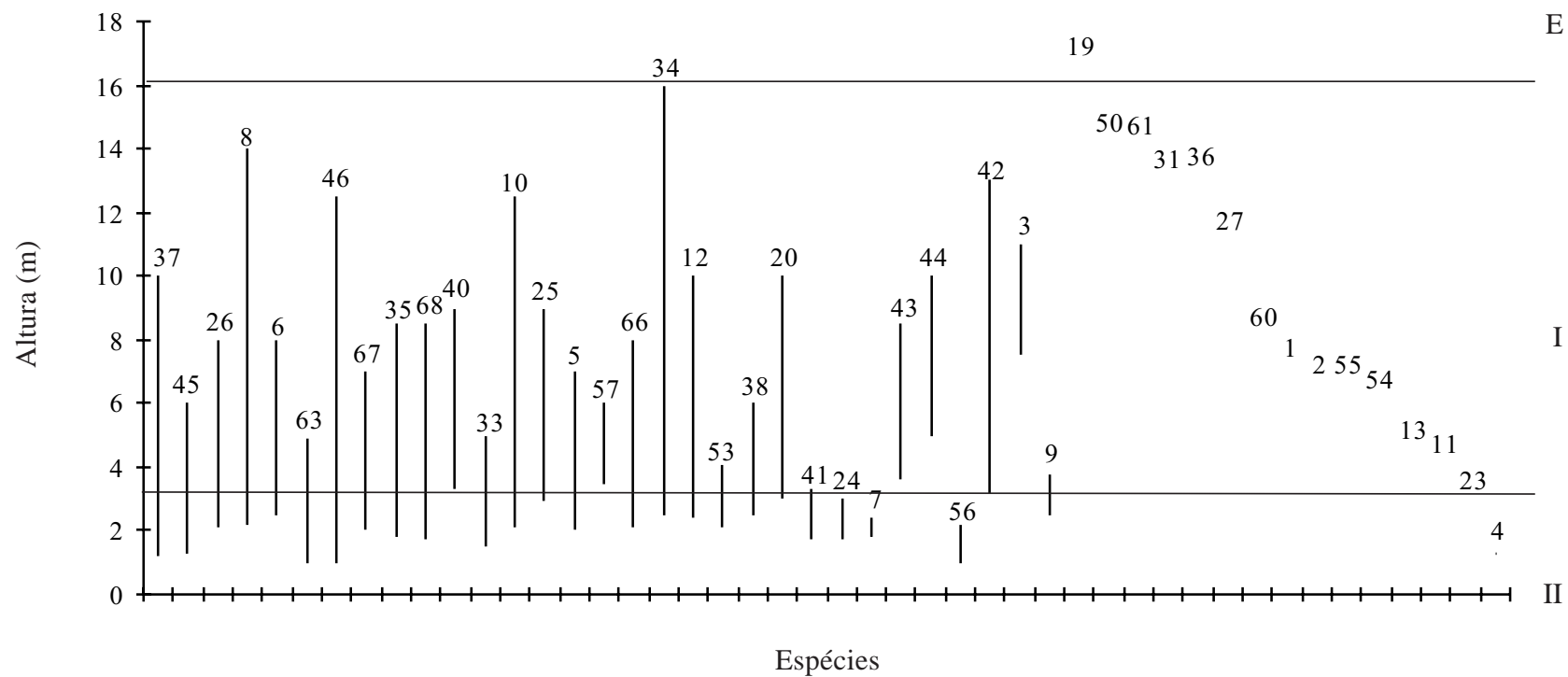

Figura 4. Alturas mínimas e máximas das espécies amostradas no Alto do Comandante, Campo Maior, PI. Espécies seqüenciadas de modo decrescente ao número de indivíduos. Os números das espécies correspondem aos números da Tab. 1. E (emergentes), I (estrato superior) e II (estrato inferior).

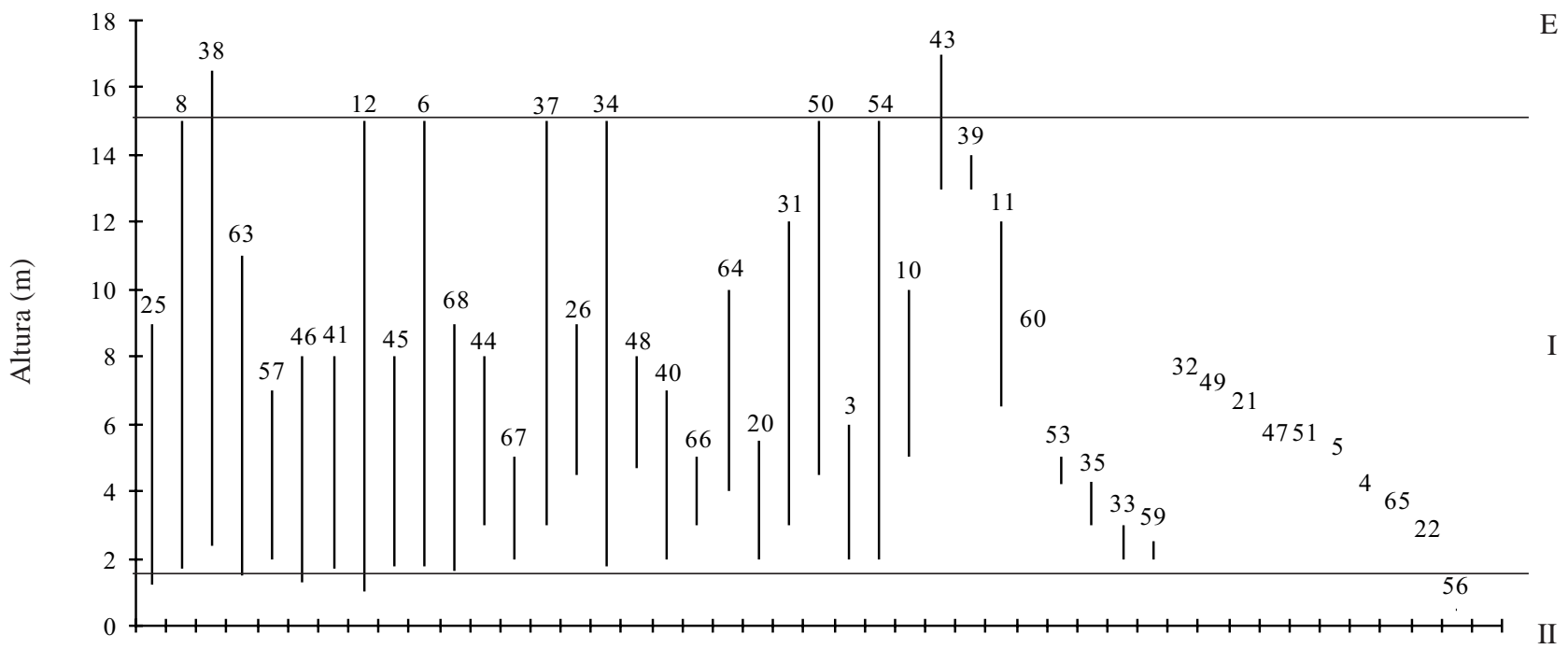

Espécies

Figura 5 Alturas mínimas e máximas das espécies amostradas no Baixão da Cobra, Campo Maio, PI. Espécies seqüenciadas de modo decrescente ao número de indivíduos. Os números das espécies correspondem aos números da Tab. 1. E (emergentes), I (estrato superior) e II (estrato inferior).

não publicados), Araújo et al. (1995) e E.M.N. Ferraz (dados não publicados). Em uma segunda divisão de similaridade, o grupo B que se desmembra em dois subgrupos, $B_{1}$, que reuniu todos os levantamentos de Carrasco e Caatinga do sedimentar realizados por Oliveira et al. (1997), Rodal et al. (1998), A.P.S. Gomes (dados não publicados), Araújo et al. (1998), Araújo \& Martins (1999), Figueirêdo et al. (2000) e Lemos \& Rodal (2002) e $\mathrm{B}_{2}$ que englobou os levantamentos do Cerrado de Castro (dados não publicados), Conceição (2000) e as áreas do presente estudo.

Os resultados indicaram que existem fortes diferenças na composição florística dos diversos tipos fisionômicos comparados em Alto do Comandante e Baixão da Cobra. Ficaram evidentes as maiores semelhanças das áreas estudadas com as áreas de Cerrado do Piauí e Maranhão. As maiores diferenças, 


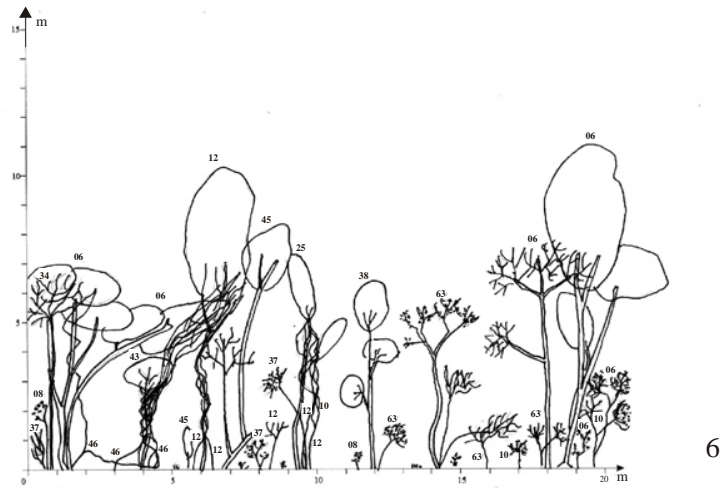

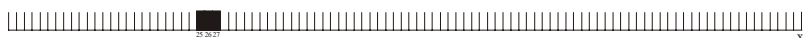

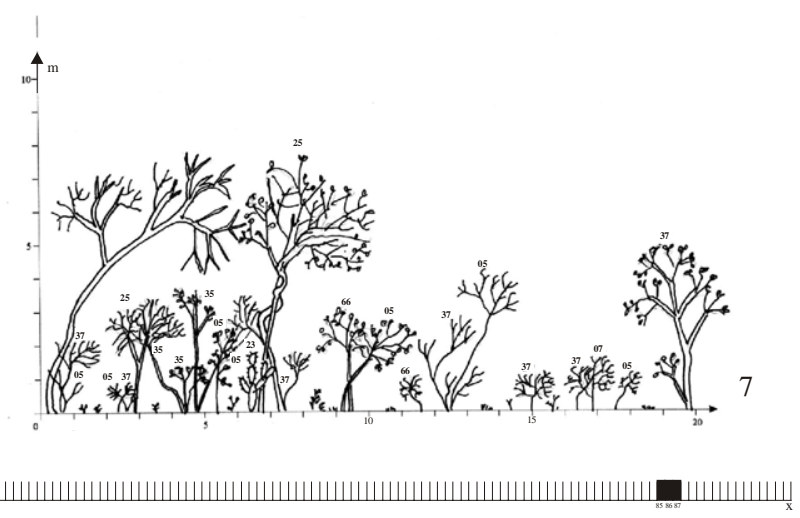

Figuras 6 e 7. Perfis esquemáticos do Alto do Comandante, Campo Maior - PI. As espécies presentes nos perfis encontram-se indicadas por meio de números conforme a numeração das espécies da Tabela 1.

por sua vez, foram observadas com os trabalhos de Caatinga do cristalino. Este caráter de transição das áreas pesquisadas e a dificuldade de enquadrá-las em um único bioma, é acentuada pela ausência de levantamentos para outras regiões do Complexo de Campo Maior. Portanto, não é possível no momento, determinar com precisão se Alto do Comandante e Baixão da Cobra apresentam composição mais próxima a algum dos tipos vegetacionais comparados anteriormente, caracterizando-se, portanto, como áreas ecotonais.

Solos - A Tab. 7 contém os resultados das análises químicas e físicas das amostras do solo da primeira trincheira, enquanto as demais não foram apresentadas por terem mostrado resultados semelhantes.

Os teores de cátions trocáveis apresentaram valores baixos quando comparados aos dados registrados pela Fernandes et al. (1993): $\mathrm{Ca}^{2+}$ variou de 0,1 a 0,$6 ; \mathrm{Mg}^{2+}$ de 0,1 a 0,$4 ; \mathrm{K}^{+}$de 0,05 a 0,18 e $\mathrm{Al}^{3+}$
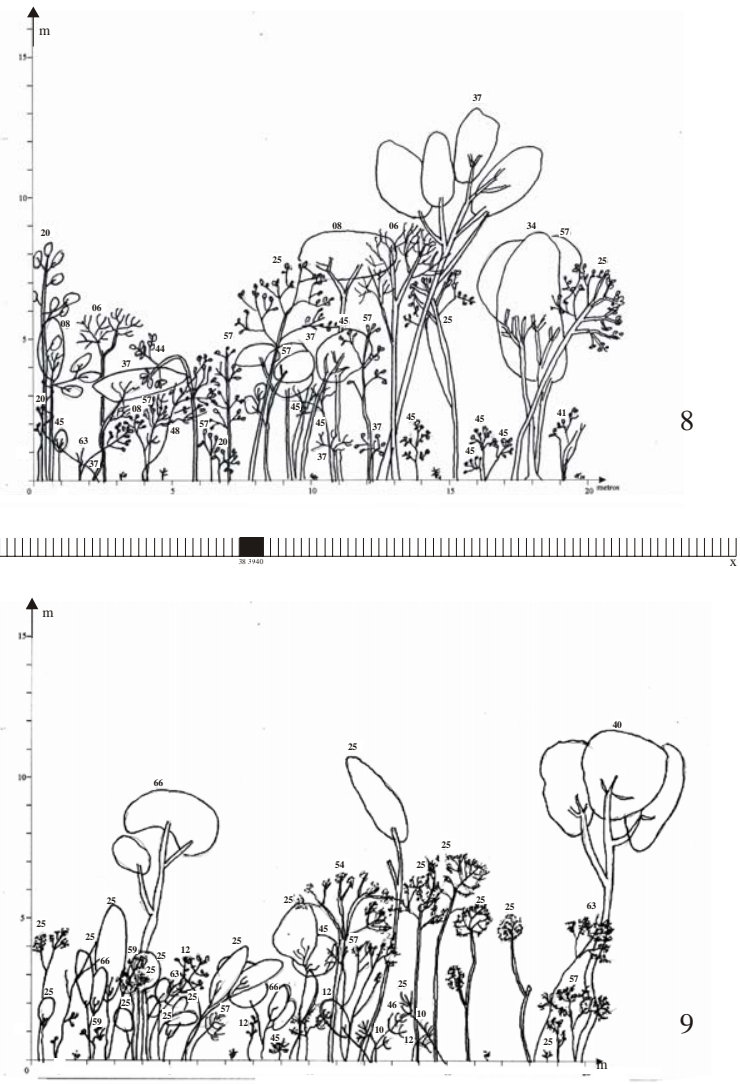

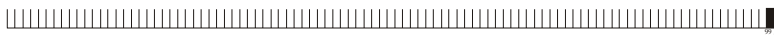

Figuras 8 e 9. Perfis esquemáticos do Baixão da Cobra, Campo Maior - PI. As espécies presentes nos perfis encontram-se indicadas por meio de números conforme a numeração das espécies da Tabela 1.

de 0,1 a 0,3 . A soma das bases ( $\mathrm{S}$ ), apresentou valores baixos, os quais que variaram de 0,6 a 1,4 . A capacidade de troca catiônica (CTC), variou de baixa à média (3,5 a 9,8). Tendo em vista que a CTC é uma conseqüência da natureza e dos componentes do solo, ligados diretamente à soma das bases (S) e acidez titulável $\left(\mathrm{Al}^{3+}+\mathrm{H}^{+}\right)$, o solo estudado apresenta uma fertilidade média.

Os valores da saturação por bases (V), foram menores que $50 \%$, caracterizando um solo distrófico. Os teores de matéria orgânica foram baixos de acordo com a Fernandes (1993), variando de 0,23 a 1,49, devido, provavelmente, à acidez do solo, uma vez que o $\mathrm{pH}$ em água indicaram valores de 4,3 a 5,2. A proporção de areia grossa, silte e argila aumentaram com a profundidade, o contrário ocorrendo com areia fina.

Os resultados das análises físicas e químicas dos horizontes das três trincheiras e a descrição dos perfis enquadram o solo, conforme os critérios do Sistema 


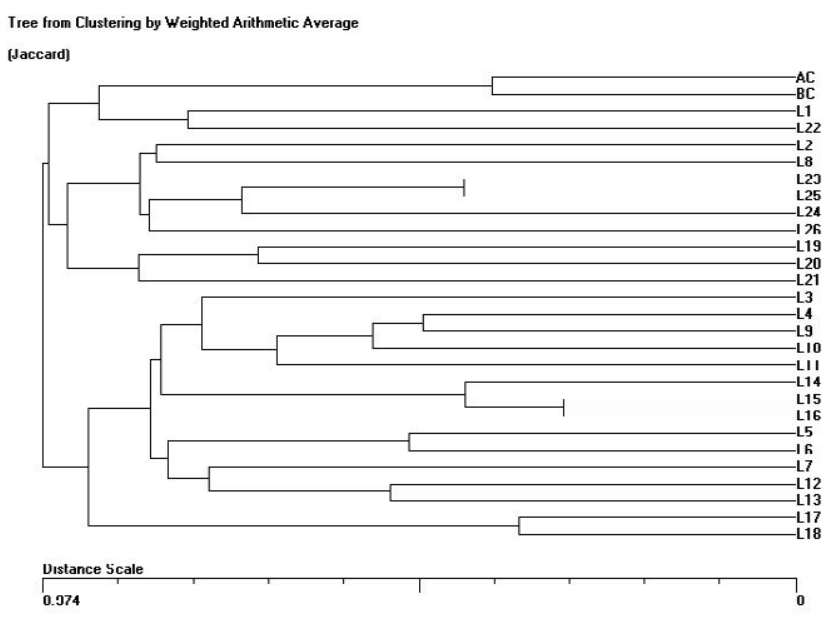

Figura 10. Dendograma de semelhança de Jaccard entre Alto do Comandante e Baixão da Cobra, com 26 levantamentos: vegetação instalada na bacia sedimentar do jatobá (21 - Rodal et al. 1998; 19 - Gomes 1999; 20 - Figueirêdo et al. 2000). Vegetação instalada sobre o cristalino (14, 15, 16, 17 E 18 - Fonseca 1991; 3, 4, 5 e 6 - Rodal 1992; 7 - Alcoforado Filho 1993; 12 e 13 - Ferraz et al. 1998; 9, 10 e 11 - Araújo et al. 1995). Cerrado (22 - Castro 1994) e Vegetação instalada sobre o sedimentar (2 - Lemos \& Rodal 2002; 8 - Oliveira et al. 1997; 23, 24 e 25 - Araújo et al. 1998; 26 - Araújo \& Martins 1999).

Brasileiro de Classificação de Solos da Embrapa, como Plintossolo Pétrico Concrecionário Distrófico, ácido léptico, de textura média esquelética, raso a pouco profundo. As áreas mais expressivas destes solos estão situadas no Médio Amazonas, na Ilha de Marajó, no Amapá, na Baixada Maranhense - Gurupi, no Pantanal, na Ilha do Bananal, TO e na região de Campo Maior do Piauí (EMBRAPA 1999).

Clima - Na área estudada, a precipitação anual é de $1.280,8 \mathrm{~mm}$, a qual é semelhante a precipitação aos encontrada por Conceição (2000) em uma área de Cerrado no Maranhão, e superior a todas as áreas de vegetação caducifólia espinhosa, caducifólia não espinhosa, transição caatinga de areia - carrasco, vegetação arbustiva perenifólia, arbustiva subcaducifólia e uma vegetação de Cerrado no Piauí (Tab. 6). Os maiores índices pluviométricos (313,9mm) foram detectados no mês de março e menor em agosto (7,2mm). A temperatura média anual é de 27 a $33,7^{\circ} \mathrm{C}$, tendo a mínima $23,4^{\circ} \mathrm{C}$ em janeiro e a máxima $38,7^{\circ} \mathrm{C}$ em novembro.

O período de excedente hídrico estende-se de janeiro a abril e o de deficiência de maio a dezembro. A evapotranspiração anual foi de 1970,0mm, o índice de aridez 20,06 e o hídrico de -14,21. Adotando a classificação de Thornthwaite \& Mather (1955), o clima ficou definido como clima subúmido seco, com grande excedente de água no verão, quinto megatérmico e com pequena amplitude térmica anual $\left(\mathrm{C}_{1} \mathrm{~W}_{2} \mathrm{~A}_{5}, \mathrm{a}\right)$.

Como considerações finais, pode-se colocar que a vegetação do Complexo de Campo Maior caracteriza-se como um ambiente sujeito a freqüentes inundações, conferindo-lhe o caráter de transição, tendendo para instabilidade. Observam-se mudanças fisionômicas em sua composição e no arranjo das espécies, passando de campo, a vários tipos fisionômicos de cerrado, caatinga, carrasco e mata semidecídua. Mesmo nos “capões”, ocorre uma variação na composição (florística e diversidade) e na distribuição das espécies (fitossociologia). Acreditase que o apanhado de dados como densidade, freqüência, altura das espécies arbóreas e a composição florística, adquiridos através deste trabalho, tenham sido o primeiro passo, e o mais coerente, para auxiliar na classificação desta fitofisionomia, bem como, subsidiar estudos futuros, pois se faz necessário e urgente a realização de outros levantamentos, pois necessita-se de informações básicas para auxiliar na implantação e consolidação de unidades de conservação necessárias para região, tendo em vista que as atividades antrópicas vêm ampliando nas áreas de tensão ecológica.

Tabela 7. Variáveis físicas e químicas analisadas nas amostras de solos coletadas no perfil 1 no Alto do Comandante, Campo Maior, PI.

\begin{tabular}{|c|c|c|c|c|c|}
\hline \multirow[t]{2}{*}{ Variáveis } & \multicolumn{5}{|c|}{ Profundidade (cm) } \\
\hline & $0-20$ & $20-55$ & $55-80$ & $80-100$ & $100-120$ \\
\hline Areia grossa $(2-0,20 \mathrm{~mm})$ & 40 & 40 & 30 & 50 & 90 \\
\hline Areia fina $(2-0,05 \mathrm{~mm})$ & 500 & 460 & 380 & 280 & 280 \\
\hline Silte $(0,05-0,002 \mathrm{~mm})$ & 370 & 380 & 440 & 450 & 450 \\
\hline Argila $(<0,002 \mathrm{~mm})$ & 90 & 120 & 150 & 180 & 180 \\
\hline pH em água & 4,70 & 4,50 & 4,30 & 5,00 & 5,10 \\
\hline pH em KCL & 3,90 & 3,80 & 3,90 & 4,20 & 4,40 \\
\hline $\begin{array}{l}\text { Condutividade elétrica } \\
\text { (mS/cm) }\end{array}$ & 0,10 & 0,10 & - & - & - \\
\hline $\mathrm{Ca}^{2+}\left(\mathrm{Cmol} / \mathrm{dm}^{3}\right)$ & 0,30 & 0,20 & 0,10 & 0,20 & 0,20 \\
\hline $\mathrm{Mg}^{2+}\left(\mathrm{Cmol} / \mathrm{dm}^{3}\right)$ & - & 0,30 & 0,40 & 0,40 & 0,30 \\
\hline $\mathrm{K}^{+}\left(\mathrm{Cmol} / \mathrm{dm}^{3}\right)$ & 0,08 & 0,05 & 0,06 & 0,07 & 0,13 \\
\hline $\mathrm{Na}^{+}\left(\mathrm{Cmol} / \mathrm{dm}^{3}\right)$ & 0,20 & 0,17 & 0,19 & 0,24 & 0,20 \\
\hline $\mathrm{Al}^{3+}\left(\mathrm{Cmol} / \mathrm{dm}^{3}\right)$ & 0,20 & 0,20 & 0,20 & - & - \\
\hline $\mathrm{S}\left(\mathrm{Cmol} / \mathrm{dm}^{3}\right)$ & 0,60 & 0,70 & 0,80 & 0,90 & 0,80 \\
\hline $\mathrm{T}\left(\mathrm{S}+\mathrm{H}^{+}+\mathrm{Al}^{3+}\right)$ & 4,20 & 4,50 & 3,50 & 3,50 & 3,80 \\
\hline V (\%) $(100 \mathrm{~S} / \mathrm{T})$ & 14,00 & 16,00 & 23,00 & 26,00 & 21,00 \\
\hline $\mathrm{m}(\%)\left(100 \mathrm{Al}^{3+} / \mathrm{S}+\mathrm{Al}^{3+}\right)$ & 25,00 & 22,00 & 20,00 & - & - \\
\hline Carbono (g/Kg) & 5,40 & 3,00 & 1,38 & 2,10 & 2,40 \\
\hline Nitrogênio (g/Kg) & 0,47 & 0,26 & 0,12 & 0,18 & 0,21 \\
\hline $\mathrm{C} / \mathrm{N}$ & 11 & 12 & 12 & 12 & 11 \\
\hline Matéria orgânica (\%) & 0,93 & 0,51 & 0,23 & 0,36 & 0,41 \\
\hline
\end{tabular}




\section{Referências bibliográficas}

Araújo, E.L.; Sampaio, V.S.B. \& Rodal, M.J.N. 1995. Composição florística e fitossociológica de três áreas de caatinga de Pernambuco. Revista Brasileira de Biologia 55(4): 595-607.

Araújo, F.S.; Sampaio, E.V.S.B.; Rodal, M.J.N. \& Figueiredo, M.A. 1998. Organização comunitária do componente lenhoso de três áreas de carrasco em Novo Oriente-CE. Revista Brasileira de Biologia 58(1): 85-95.

Araújo, F.S. \& Martins, F.R. 1999. Fisionomia e organização da vegetação do carrasco no Planalto da Ibiapaba, estado do Ceará. Acta Botanica Brasilica 13(1): 1-14.

Barkman, J.J. 1978. Synusial approaches to classification. Pp. 111-165. In: R.H. Whittaker. Classification of plant communities. W. Junk, The Hague.

Brummitt, R.K. \& Powell, C.E. 1992. Author of plant names. London, Kew, Royal Botanic Gardens.

Castro, A.A.J.F. 2000. Cerrados do Brasil e do Nordeste: produção, hoje, deve também incluir manutenção da biodiversidade. Pp. 79-87. In: A.H. Benjamin \& J.M.C. Sícoli (eds.). Agricultura e Meio Ambiente. São Paulo, IMESP.

Castro, A.A.J.F. \& Martins, F.R. 1999. Cerrados do Brasil e do Nordeste: caracterização, área de ocupação e considerações sobre a sua fitodiversidade. Pesquisa em Foco 7(9): 147-178.

Castro, A.A.J.F. \& Martins, F.R. \& Fernandes, A.G. 1998. The woody flora of cerrado vegetation in the state of Piauí, northeastern Brazil. Edinburgh Journal of Botany 55(3): 455-472.

CEPRO. 1992. Perfil dos Municípios. Teresina.

CEPRO. 1996a. Diagnóstico das Condições Ambientais do Estado Piauí. Teresina.

CEPRO. 1996b. Piauí: Caracterização do Quadro Natural. Teresina.

Cronquist, A. 1988. The evolution and classification of flowering plants. New York Botanical Garden. New York.

Curtis, J.T. \& Macintosh, R.P. 1950. The interrelations of analytic and synthetic characterers. Ecology 31: 434-455.

EMBRAPA. 1999. Sistema Brasileiro de Classificação de solos. Brasília, EMBRAPA Solos.

Fernandes, V.L.B. (coord.). 1993. Recomendações de adubação e calagem para o estado do Ceará. UFC. Fortaleza.

Figueirêdo, L.S.; Rodal, M.J.N. \& Melo, A.L. 2000. Florística e fitossociologia de uma área de vegetação arbustiva caducufólia no município de Buíque-Pernambuco. Naturalia 25: 205-224.
Giulietti, A.M; Harley, R.M.; Queiroz, L.P.; Barbosa, M.R.V.; Bocage-Neta, A.L. \& Figueiredo, M.A. 2002. Espécies endêmicas da caatinga. Pp. 103-118. In: E.V.S.B. Sampaio; A.M. Giulietti; J. Virgínio \& C.F.L. Gamarra-Rojas (eds.). 2002. Vegetação \& flora da Caatinga. Recife, Associação de Plantas do Nordeste - APNE.

Krebs, C.J. 1989. Ecology methodology. Printer and Brinder for R.R. Donelly \& Sons company. Cambridge. Includes index. 1 Ecology - Stastistical methods.

Lemos, J.R. \& Rodal, M.J.N. 2002. Fitossociologia do componente lenhoso de um trecho de vegetação arbustiva espinhosa no Parque Nacional Serra da Capivara, Piauí, Brasil. Acta Botanica Brasilica 16(1): 23-42.

Martins, F.R. 1991. Estrutura de uma floresta mesófila. Campinas, Editora da UNICAMP.

Mello Netto, A.V.; Lins, R.C. \& Coutinho, S.F.S. 1992. Áreas de exceção úmidas e subúmidas do semi-árido do nordeste do Brasil: estudo especial. In: Impactos de variações climáticas e desenvolvimento sustentável em regiões semi-áridas. Fundação Joaquim Nabuco/ICID. Recife, $12 \mathrm{p}$.

Oliveira, M.E.A.; Sampaio, E.V.S.B.; Castro, A.A.J.F. \& Rodal, M.J.N. 1997. Flora e fitossociologia de uma área de transição carrasco-caatinga de areia em Padre Marcos, Piauí. Naturalia 22: 131-150.

Pauwels, P.G.J. 1985. Atlas geográfico melhoramentos. 47 ed. São Paulo, Ed. Melhoramentos.

Rivas, M.P. (coord.). 1996. Macrozoneamento geoambiental da bacia hidrográfica do rio Parnaíba. Rio de Janeiro, IBGE. (Série Estudos e Pesquisas em Geociências, 4).

Rodal, M.J.N.; Andrade, K.V.S.A.; Sales, M.F. \& Gomes, A.P.S. 1998. Fitossociologia do componente lenhoso de um refúgio vegetacional no município de Buíque, Pernambuco. Revista Brasileira de Biologia 58(3): 517-526.

Shepherd, G.J. 1995. Fitopac 1 - Manual do usuário. Departamento de Botânica da UNICAMP. Campinas.

Souza, M.J.N.; Martins, M.L.R.; Soares, Z.M.L.; FreitasFilho, M.R.; Almeida, M.A.G.; Pinheiro, F.S.A.; Sampaio, M.A.B.;Carvalho, G.M.B.S.; Soares, A.M.L.; Gomes, E.C.B. \& Silva, R.A. 1994. Redimensionamento da região semi-árida do Nordeste do Brasil. In: Conferência e Seminário Latino-Americano da Desertificação. Fortaleza: Fundação Esquel do Brasil,s 25p.

Thornthwaite, C.W. \& Mather, J.R. 1955. The water balance. Centerton: Laboratory of Climatology. 104p. (Publication in Climatology, 8). 